\title{
Considerações biomecânicas sobre suporte, retenção e estabilidade em prótese parcial removível convencional: uma revisão narrativa da literatura
}

\author{
Biomechanical considerations on support, retention \\ and stability in conventional removable partial \\ dentures: a narrative review of the literature
}

\section{Viviane Maria Gonçalves de Figueiredo' ${ }^{1}$ (1) Larissa Micaella Moraes Arcoverde ${ }^{2}$ (1) Manassés Tercio Vieira Grangeiro 3 (1)}

${ }^{1}$ Autora para correspondência. Universidade Federal do Pernambuco (Recife). Pernambuco, Brasil. vivi_mfigueiredo@yahoo.com.br ${ }^{2}$ Universidade Federal do Pernambuco (Recife). Pernambuco, Brasil. laariarco@gmail.com ${ }^{3}$ Universidade Estadual Paulista (São José dos Campos). São Paulo, Brasil. terciomanasses@gmail.com

\begin{abstract}
RESUMO | OBJETIVO: objetivou-se apresentar considerações biomecânicas sobre suporte, retenção e estabilidade em prótese parcial removível convencional, por meio de uma revisão narrativa da literatura. METODOLOGIA: Nesta revisão narrativa da literatura, buscou-se a literatura através de bases de dados como Google Acadêmico, BVS, Scielo, Pubmed e literatura especializada sobre o tema, como livros; utilizando os termos-chaves Biomecânica (biomechanical) e Prótese Parcial Removível (removable partial dentures). Como critérios de inclusão foram considerados estudos que abordassem biomecânica de PPR convencionais, ou seja, a grampo; enquanto os critérios de exclusão comtemplaram estudos que abordassem o uso de PPR não convencionais, como prótese com attachements e PPR com uso de implantes. A cronologia da literatura não foi um critério de seleção adotado, devido à escassa abordagem do tema nas bases de dados. Buscou-se literatura nos idiomas inglês e português, e as buscas foram realizadas no período de junho de 2020. RESULTADOS: As bases de dados BVS, Scielo, Pubmed não apresentaram nenhum estudo com os unitermos utilizados na busca bibliográfica; 04 artigos e 01 monografia de especialização foram selecionados no Google Acadêmico publicados entre 1970 e 2017, e 05 livros também foram selecionados, por serem os mais relevantes sobre prótese parcial removível disponíveis no país. CONSIDERAçõES FINAIS: O estudo biomecânico da prótese parcial removível convencional deve ser conduzido com base no suporte, retenção e estabilidade; quando identificadas características clínicas que interfiram em mecanismos de retenção e estabilidade, faz-se necessária a adoção de estratégias para minimizar a movimentação da prótese. Tais estratégias dão maior recobrimento à área chapeável, montagem até $1^{\circ}$ molar, ajuste oclusal com forças dirigidas ao longo eixo dos dentes artificiais, desoclusão dos dentes posteriores em lateralidade e protusão; retentores indiretos localizados o mais distante da linha de fulcro.
\end{abstract}

PALAVRAS-CHAVE: Prótese Parcial Removível. Planejamento de prótese dentária. Modelos dentários.
ABSTRACT | OBJECTIVE: the objective was to present biomechanical considerations on support, retention and stability in conventional removable partial dentures, through a narrative review of the literature. METHODOLOGY: In this narrative review of the literature, literature was sought through databases such as Google Scholar, VHL, Scielo, Pubmed and specialized literature on the subject such as books; using the key terms Biomechanics (biomechanical) and Removable Partial Dentures (removable partial dentures). Inclusion criteria were studies that addressed conventional PPR biomechanics, that is, the staple; while the exclusion criteria cover studies that addressed the use of unconventional PPR, such as prosthesis with attachements and PPR with the use of implants. The chronology of the literature was not a selection criterion adopted, due to the scarce approach to the topic in the databases. Literature was searched for in English and Portuguese, and the searches were carried out in the period of June 2020. RESULTS: The BVS, Scielo, Pubmed databases did not present any study with the terms used in the bibliographic search; 04 articles and 01 specialization monograph were selected on Google Scholar published between 1970 and 2017 and 05 books were also selected, as they are the most relevant on removable partial dentures available in the country. FINAL CONSIDERATIONS: The biomechanical study of the conventional removable partial denture should be conducted based on support, retention and stability; when clinical characteristics are identified that interfere with retention and stability mechanisms, it is necessary to adopt strategies to minimize the movement of the prosthesis. Such strategies are greater covering of the pliable area, mounting up to 1 - molar, occlusal adjustment with forces directed along the long axis of the artificial teeth, posterior teeth disocclusion in laterality and protrusion; indirect retainers located the furthest from the fulcrum line.

KEYWORDS: Removable Partial Dentures. Dental dentures planning. Dental models. 


\section{Introdução}

A prótese parcial removível (PPR) é uma importante estratégia reabilitadora, apresentando resultados aceitáveis mesmo durante um longo período de acompanhamento. No entanto, muitos clínicos apresentam dificuldades em conduzir a terapêutica com PPR efetivamente, do ponto de vista biológico, mecânico e estético ${ }^{1}$. Alcançar um tratamento bemsucedido depende dos esforços do cirurgião-dentista, da equipe técnica e cuidados do paciente. As falhas e complicações que possam ocorrer em PPR depende principalmente do dentista, pois este profissional deve prever e corrigir erros durante confecção da prótese e ser capacitado a executar todas as fases do tratamento ${ }^{2}$.

O planejamento ausente ou incorreto da estrutura metálica é uma das principais causas de insucesso desta reabilitação protética ${ }^{1}$, principalmente quando não se avalia a condição biomecânica do arco parcialmente edêntulo ${ }^{3}$. É frequente que o cirurgião-dentista delegue o planejamento do desenho da prótese ao técnico de prótese dentária, que não apresenta conhecimento biológico dos dentes pilares, fibromucosa, osso alveolar residual, oclusão ou musculatura paraprotética ${ }^{5}$. Devido ao seu conhecimento científico, o cirurgião-dentista é o profissional responsável para prever e corrigir falhas ${ }^{6}$.

Muitos consideram esse planejamento complexo, principalmente no que se refere ao estudo biomecânico do arco sobre a transmissão de carga mastigatória na PPR e o comportamento do suporte mucoso e dental frente à absorção destas forças. Controlar a ação das forças que atuam sobre a PPR de forma que não ultrapassem o limite de tolerância fisiológica dos tecidos orais e não cause danos ao sistema estomagnático é crucial para longevidade do tratamento ${ }^{3}$.

Evidências científicas sobre esta temática são escassas na literatura, como também as considerações biomecânicas se apresentam de certa forma complexas e de difícil entendimento para a classe odontológica. Assim, é necessária a divulgação de um conhecimento que torne a aplicação da biomecânica em PPR de mais fácil compreensão e favoreça o planejamento protético. Dessa forma, objetivou-se apresentar considerações biomecânicas sobre suporte, retenção e estabilidade em prótese parcial removível convencional por meio de uma revisão narrativa da literatura.
Metodologia

Nesta revisão narrativa da literatura, buscou-se a literatura através de bases de dados como Google Acadêmico, BVS, Scielo, Pubmed e literatura especializada sobre o tema, como livros; utilizando os termos-chaves Biomecânica (biomechanical) e Prótese Parcial Removível (removable partial dentures). Como critérios de inclusão foram considerados estudos que abordassem biomecânica de PPR convencionais, ou seja, a grampo; enquanto os critérios de exclusão comtemplaram estudos que abordassem o uso de PPR não convencionais, como prótese com attachements e PPR com uso de implantes. A cronologia da literatura não foi um critério de seleção adotado, devido à escassa abordagem do tema nas bases de dados. Buscou-se literatura nos idiomas inglês e português, e as buscas foram realizadas no período de junho de 2020.

\section{Resultados}

As bases de dados BVS, Scielo, Pubmed não apresentaram nenhum estudo com os unitermos utilizados na busca bibliográfica; 04 artigos e 01 monografia de especialização foram selecionados no Google Acadêmico publicados entre 1970 e 2017, e 05 livros também foram selecionados por serem os mais relevantes sobre prótese parcial removível disponíveis no país.

\section{Revisão de literatura}

\section{Por que estudar a biomecânica em PPR?}

As próteses parciais removíveis sofrem ação de forças funcionais ou não funcionais, que buscam removê-la de posição. As movimentações podem ocorrer através da ação da gravidade, alimentos de consistência dura ou pegajosa, ação da musculatura paraprotética, oclusão, parafunção e fonação. Tais movimentações geram instabilidade à prótese e desconforto ao paciente, como geram tensão aos dentes remanescentes e aos tecidos moles do arco parcialmente edêntulo. Essa tensão não deve exceder o nível de tolerância fisiológica dos tecidos orais e elementos dentais, caso contrário, terão consequências traumáticas para essas estruturas $^{ }$. O Estudo clínico de Jorge e colaboradores $\stackrel{8}{ }$ avaliou pacientes reabilitados com PPR com arcos Classe III de 
Kennedy Modificação 1 e Classe I de Kennedy quanto à mobilidade dos dentes pilares. Os resultados mostram elevação da mobilidade dentária em pacientes que utilizaram por 5 anos PPR com extremidades livres, comparado aos casos de Classe III Modificação 1. Contudo, os autores afirmam que não foram mudanças significativas entre os grupos. E talvez estes achados possam ter ocorrido devido às mudanças fisiológicas orais ou pela ausência do estudo biomecânico do arco, gerando danos ao suporte dental.

O controle do movimento sob cargas funcionais é crítico. Desse modo, o estudo da biomecânica busca uma solução na confecção de um desenho para prótese que seja eficiente do ponto de vista mecânico, neutralize ou minimize possíveis movimentações da prótese, e biológico, na manutenção da integridade aos elementos dentais, periodonto, rebordo ósseo e sistema estomatognático ${ }^{ }$. Podem ocorrer movimentos de rotação, que implicam em uma movimentação de um corpo ao redor de seu eixo, e translação, que significa movimentação de vários pontos de um corpo sobre um eixo distante (deslizamento de um corpo 3 . Ambos movimentos podem ocorrer simultaneamente ${ }^{3,7}$; embora, nesta revisão, tenham sido focados apenas os movimentos rotacionais da PPR, por serem os mais relatados na literatura.

Inicialmente, serão apresentados os movimentos de próteses com extremos livres (ausência de dentes posteriores), por apresentarem maior complexidade decorrente da diferença entre a resiliência da membrana periodontal em relação à fibromucosa; deste modo, promove a movimentação sobre a área basal da PPR e faz com que os dentes pilares recebam elevada força de torque. As próteses que apresentam extremos distais possuem eixo de rotação real em relação à linha de fulcro com movimentos de alavanca; e os casos de próteses para arcos com três ou mais dentes pilares (com ausência de extremo livre) apresentam eixo de rotação virtual, pois apresentam distribuição de dentes que favorece a estabilidade e formam um plano ou superfície ${ }^{3}$.

Pelo mesmo princípio adotado na engenharia mecânica, as próteses com extremo livre representam um sistema de alavancas através da extensão distal. A alavanca é considerada uma máquina simples que repousa sobre um apoio, o ponto de apoio é chamado de fulcro. Então, a alavanca pode se mover em torno do fulcro e este apoio pode ser representado pelos elementos dentais adjacentes ao espaço protético ${ }^{7}$.
A linha imaginária do fulcro passa pelos apoios mais distais ou posteriores do arco, representando uma zona de instabilidade através de um braço de resistência voltado para região dentada e um braço de potência voltado para a área edêntula. A força que incide sobre os dentes artificias, dos extremos livres, promovem movimentos de alavanca em torno da linha de fulcro, que podem gerar a compressão do rebordo residual e assim acelerar a absorção óssea, causar lesões de trauma na fibromucosa e danos periodontais (mobilidade) aos elementos dentais. Quanto maior braço de resistência (área dentada), comparado ao braço de potência (área edêntula), maior será a diminuição dos danos aos dentes remanescentes e ao tecido mucoso que possam surgir. Caso contrário, maior braço de potência, comparado ao braço de resistência, poderá favorecer danos irreversíveis aos suportes do arco parcialmente edêntulo?

O movimento rotacional se dá quando a força é aplicada na sela protética, e esta sofre rotação em relação aos três planos cranianos. Embora o movimento real da prótese possa ser pequeno, uma força de alavanca pode ser imposta ao dente pilar, que é prejudicial quanto à manutenção da prótese ${ }^{7}$. A rotação no plano sagital se dá por meio de movimentação vertical das selas; no caso da mastigação de alimentos mais consistentes, a sela movimenta-se em direção ocluso-gengival, contra os tecidos moles, condição de rotação distal. No caso de alimentos pegajosos, chama-se rotação mesial, em que a sela se distancia dos tecidos moles ${ }^{3,7,}$. Na rotação do plano frontal, as selas se movem em direção rotacional sobre o rebordo residual. Este tipo de rotação ocorre principalmente em casos de mastigação unilateral e interferência oclusal em lateralidade. Já a rotação no plano horizontal se dá por movimentos protéticos que ocorrem durante a função. As forças oclusais diagonais e horizontais são exercidas na prótese parcial, decorrentes da inclinação das cúspides em movimentação de lateralidade ou protusão $0^{3,1}$.

Em uma prótese parcial removível com ausência da extensão distal, os movimentos da base são evitados pelos apoios nos dentes pilares e componentes estabilizadores, como conector menor e conector maior. A presença de dois elementos dentais entre o espaço protético faz com que suportem a transmissão da força sobre a prótese, e estes não configuram movimentos de alavanca sobre o arco. Porém, a rotação no plano horizontal ocorre em todas as próteses parciais removíveis, sendo os únicos movimentos de alguma significância em PPR sem extremos livres ${ }^{7}$. 


\section{Suportes da Prótese Parcial Removível}

Os suportes atuam na tentativa de resistir a forças que buscam deslocar a PPR da posição de assentamento, sentido ocluso-gengival ${ }^{3}$. Os suportes da PPR são representados pelos elementos dentais, ligamento periodontal, fibromucosa e rebordo alveolar residual, e correspondem ao fator biológico frente ao planejamento protético. Os suportes também estão interligados aos mecanismos de retenção e estabilidade da prótese ${ }^{10}$. Como a prótese parcial removível, apresenta suporte dental e/ou mucoso se faz necessário compreender a transmissão de carga mastigatória, seja dentossuportada ou dentomucossuportada ${ }^{5}$.

Nas próteses dentossuportadas, os elementos dentais naturais recebem a carga por meios dos apoios e pelas selas adjacentes a tais, transmitindo a força ao osso alveolar pelas fibras do ligamento periodontal. As áreas de mucosa que revestem os espaços protéticos entre os dentes suportes não recebem carga, apresentando apenas uma relação de contato com a área basal da PPR, geralmente casos de Classe III e Classe IV de Kennedy 5 .

As próteses dentomucossuportadas apresentam a transmissão de carga advinda dos dentes artificiais sobre o suporte mucoso e por meio do suporte dental ${ }^{5,7}$, e geralmente englobam casos com a presença de extremos livres, como nos casos de Classe I e Classe II de Kennedy ${ }^{5}$. Qualquer prótese parcial extensa de Classe III ou IV de Kennedy que não tenha suporte adequado dos pilares e longos espaços protéticos recai nesta mesma categoria ${ }^{7}$. A carga recebida pelo rebordo residual é amortecida pela fibromucosa, e assim transmitida a força compressiva ao osso alveolar residual. Parte da força mastigatória é eliminada pela resiliência da fibromucosa e a força absorvida pelo osso residual promove a compressão do mesmo ${ }^{5}$.

Para que o suporte dental seja elegido para suportar as cargas da mastigação advindas da PPR, se faz necessário apresentar adequado suporte periodontal livre de condições cariosas e não cariosas, não apresentar patologias apicais e ósseas, integridade coronária e favorável inclinação no arco, ou seja, sem condições de giroversão que dificultem a execução da prótese $\mathrm{e}^{10}$. Os elementos dentais de suporte denominados de dentes pilares são os dentes remanescentes, estando esses adjacentes ao espaço edêntuIo ${ }^{5,7}$. Fatores como número e distribuição de dentes pilares são essenciais neste planejamento; embora a distribuição dos mesmos no arco apresente importância superior ao número $3,5,9,10$. Condições de distribuição de dentes pilares são apresentadas no Quadro 1. De certa forma, essa distribuição define a transmissão de carga mastigatória da prótese a ser confeccionada; quando a figura geométrica abrange os espaços protéticos, temos uma prótese dentossuportada; quando há espaços edêntulos não incluídos nesta figura, a prótese é dentomucossuportada ${ }^{5}$.

Vale ressaltar que os suportes dentais, além de suportarem a carga mastigatória, também apresentam fins de retenção e estabilidade da prótese ${ }^{5}$, logo mais tratados nesta revisão. Como os apoios são importantes nesse planejamento por transmitirem a carga mastigatória ao longo eixo do suporte dental, são necessárias cavidades dentais, (nichos) para acomodá-los, a fim de evitar contatos prematuros e futuros danos periodontais aos dentes pilares $\stackrel{9}{\text {. }}$

A ausência de planejamento protético pode levar a mudanças que afetam o suporte do periodonto, gerando áreas de inflamação e ulceração, bolsas periodontais, maior mobilidade e, em mais casos graves, perda ou fratura de dente, principalmente dentes do pilar, porque a rigidez do metal transfere o estresse para o tecido periodontal e mucoso? . Em um estudo retrospectivo realizado por Correia e Colaboradores ${ }^{11}$, observou-se diferença estatisticamente significativa quanto aos danos periodontais em dentes pilares, os quais apresentaram recessão gengival e mobilidade dentária, principalmente em casos mandibulares Classe I de Kennedy comparados a casos Classe III de Kennedy.

Em relação ao suporte mucoso, destacam-se os espaços protéticos em contato com as selas, que são áreas que interferem diretamente no prognóstico de casos dentomucossuportados, já que a maior parte da força mastigatória é transmitida ao osso alveolar residual, quando comparada ao dente pilar ${ }^{5}$. Assim, deve-se avaliar a resiliência da fibromucosa, o formato e comprimento do rebordo alveolar residual que influenciam significativamente o volume de suporte disponível e a estabilidade em casos de extremidade livre $^{7}$. Certas condições de resiliência da fibromucosa promovem prognóstico desfavorável ao suporte e estabilidade da PPR, deste modo, é preciso estabelecer medidas para minimizar os possíveis danos, como a aceleração da reabsorção óssea ${ }^{3,5,10}$. (Quadro1). 


\begin{tabular}{|c|c|c|c|c|c|c|c|}
\hline 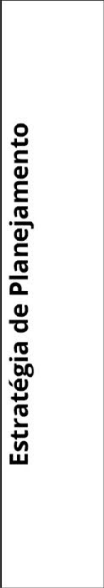 & 1 & 1 & 1 & 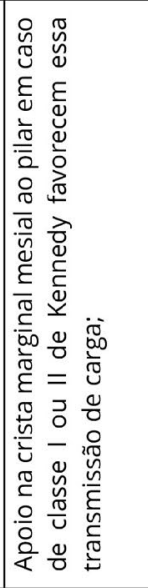 & 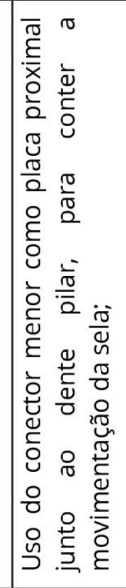 & 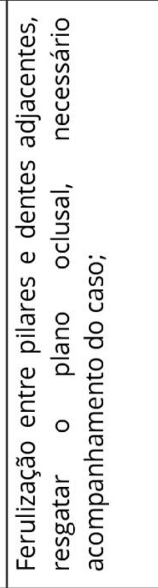 & 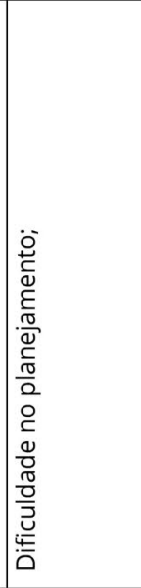 \\
\hline 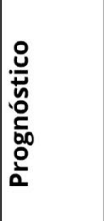 & : & 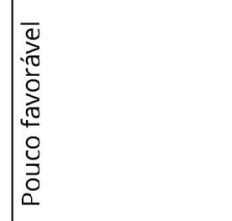 & 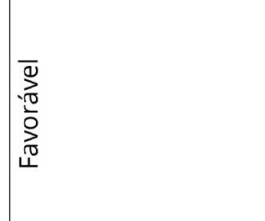 & & 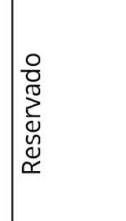 & 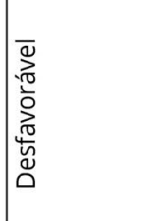 & 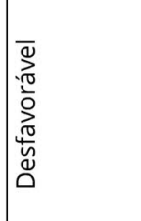 \\
\hline 悹 & 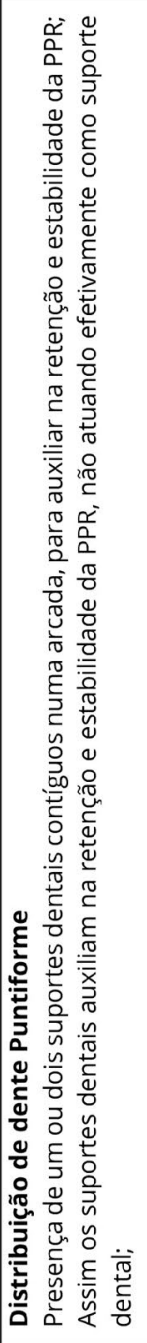 & 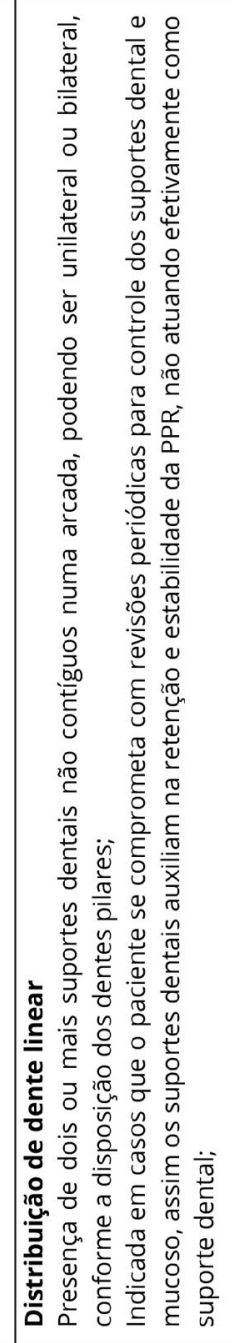 & 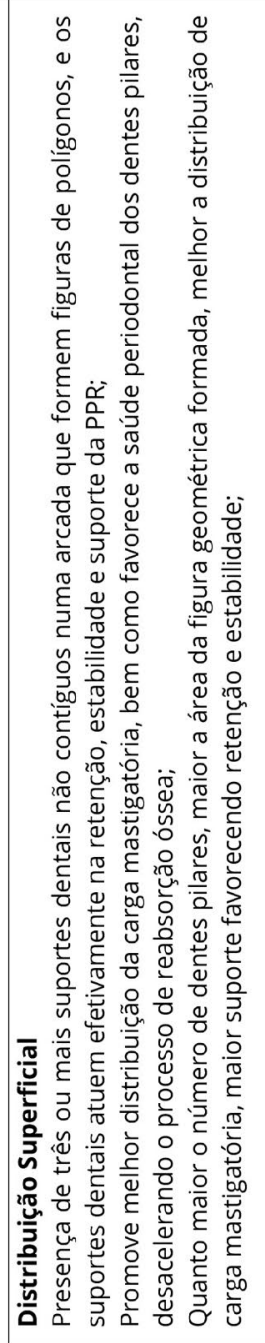 & 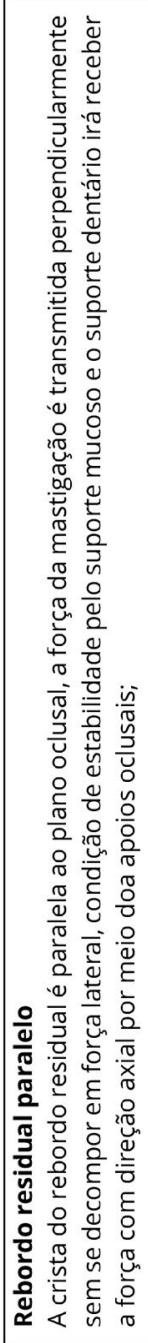 & 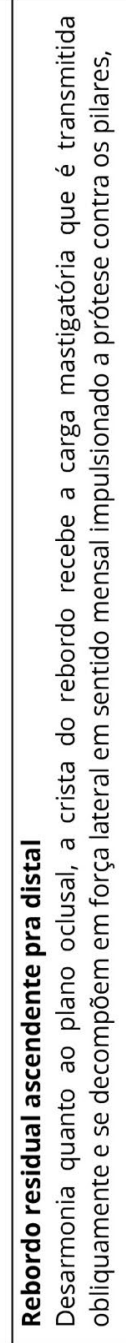 & 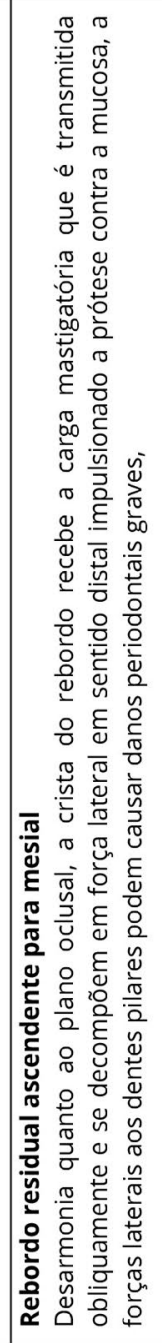 & 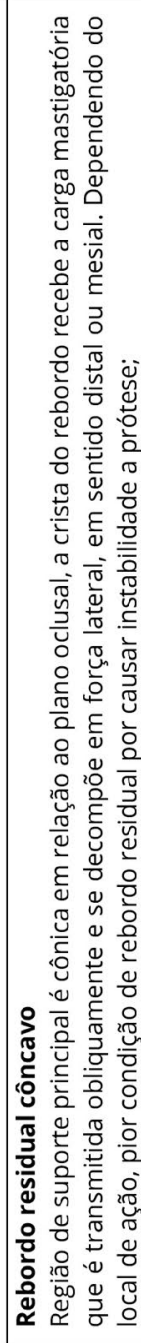 \\
\hline 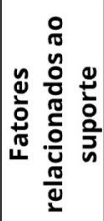 & 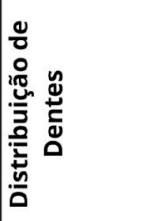 & & & 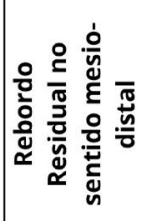 & & & \\
\hline
\end{tabular}




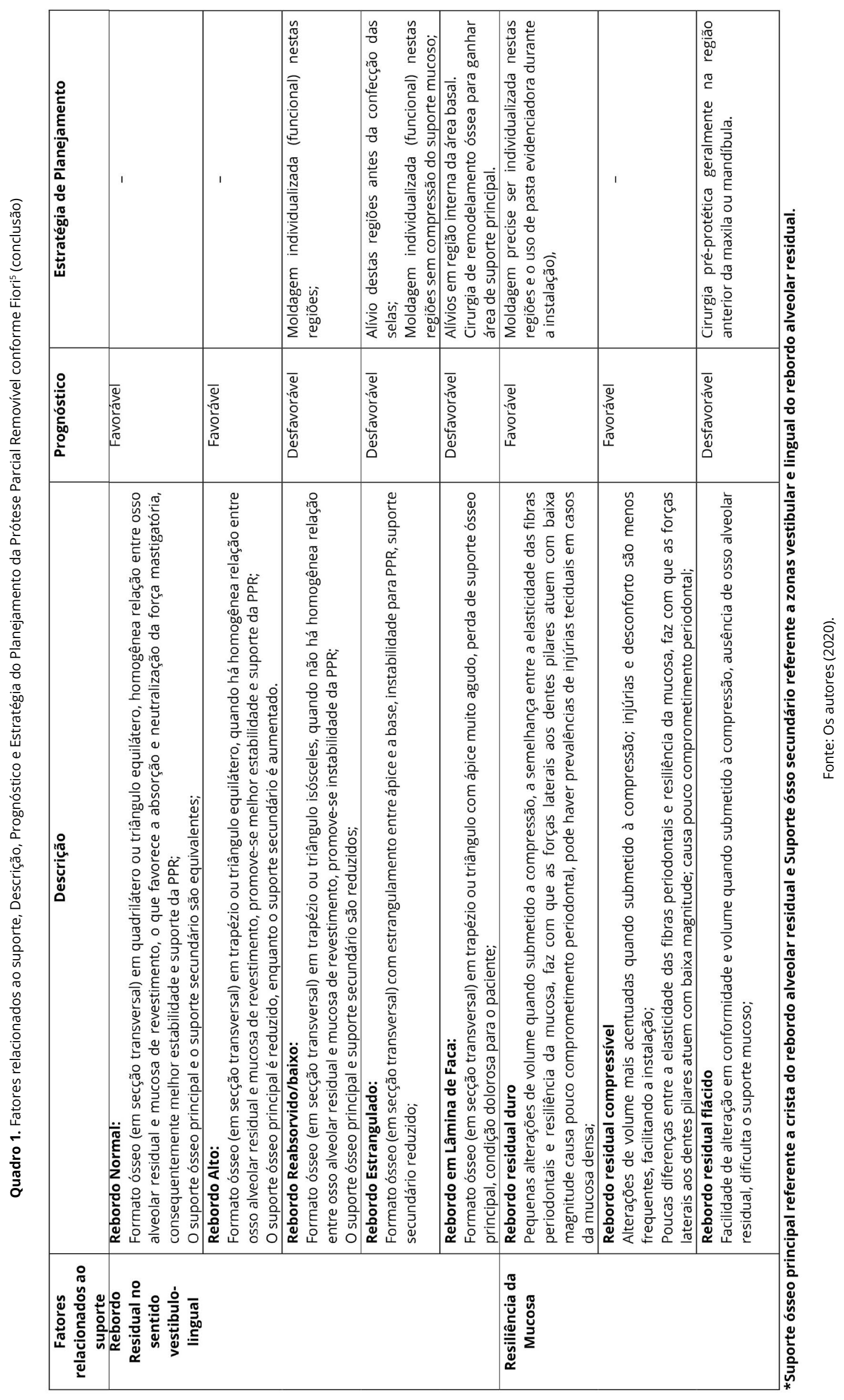


Em casos de prótese dentomucossuportada, a estabilidade na área basal é desejada, pois o suporte primário do osso alveolar residual recebe maior parte da carga mastigatória, e o suporte secundário é primordial na estabilidade lateral da prótese, impedindo que essas forças atuem sobre os dentes pilares. Esta instabilidade da área basal se evidencia através de movimentos de báscula em torno da linha de fulcro, por causa de diferença da natureza dos tecidos dentais e mucoso na absorção de carga mastigatória ${ }^{3}$. Também pode ser consequência de um desenho inadequado, forma do rebordo residual ou condição de resiliência mucosa ${ }^{5}$; além da extensão da área edêntula, que quanto maior, mais potencializados os movimentos da PPR?

\section{Mecanismos de Retenção}

A retenção da prótese parcial removível pode se apresentar fisiológica e física. A fisiológica é alcançada pelo equilíbrio entre a confecção da prótese e os músculos paraprotéticos. Como também, através dos princípios de zona neutra, as forças vestíbulo-linguais auxiliam na manutenção da posição da prótese. Já a retenção física se dá através da confecção da prótese sobre os princípios de adesão, coesão e pressão atmosférica, que ocorrem entre sela e fibromucos 3 .

Por fim, a retenção mecânica representada pelos grampos de retenção em retentores diretos (os dentes pilares) e retentores indiretos (o suporte dentário mais distante da linha fulcro); os últimos melhoram também a estabilidade e suporte da PPR. Para Carr e Brown ${ }^{7}$ e $\operatorname{Todescan}^{10}$, uma retenção satisfatória se dá através da retenção primária, com o uso de elementos de retenção sobre os dentes pilares (os grampos de retenção), e uma retenção secundária, dependente do retentor indireto, contato dos conectores menores com os planos-guia e adaptação das bases da prótese e do conector maior com o tecido subjacente.

A ação retentiva sobre os dentes pilares não deve ser excessiva, para não dificultar a retirada da prótese pelo paciente e havendo a possibilidade de danos biológicos sobre o suporte dental. Desta forma, é necessário estabilizar as ações retentivas sobre os suportes dentais no sentido vertical e horizontal, ou seja, princípios da reciprocidade. A Reciprocidade Vertical ocorre pelo contato simultâneo no elemento dental do grampo de retenção na face vestibular e grampo de oposição na face lingual, até o assentamento final da prótese. A flexibilidade da ponta ativa do grampo de retenção sobre o suporte dental, não deve promover deslocamento dental em sentido contrário, pois a estabilidade é alcançada pelo grampo de oposição rígido que se contrapõe ao grampo de retenção $3,7, \underline{\text { I.9. }}$.

Na Reciprocidade Horizontal, o grampo de retenção e oposição devem ser planejados para que as forças entre tais sejam nulas. Para tal, os braços de retenção e oposição não devem ultrapassar $180^{\circ}$ da circunferência da coroa, promovendo, assim, a estabilidade sobre o suporte dental e neutralizando as forças em sentidos opostos ${ }^{3,7,9}$. Os grampos da prótese parcial removível não circundam o dente tão completamente como o retentor de uma prótese parcial fixa. Portanto, estes devem ser desenhados para abraçar mais da metade da circunferência, a fim de possibilitar que a prótese mantenha a posição mesmo sob a influência de cargas mastigatórias horizontais ${ }^{ }$.

A retenção deve ser avaliada em cada dente pilar e em relação ao ângulo de convergência cervical formado pela inclinação dental abaixo do equador protético e a trajetória de inserção da prótese. Quanto mais baixo for este ângulo, mais cervical o posicionamento do terminal retentivo do grampo, e maior a altura vertical de contato do grampo de retenção com a superfície dental, o que minimiza a perda de retenção da prótese em casos de rotação mesial. Quando o ângulo de convergência cervical é maior, o terminal ativo do grampo de retenção fica muito próximo ao equador protético. Essa situação é desfavorável pois reduz a área de deslocamento vertical do grampo, podendo levar a perda de retenção da prótese. Este ângulo também determina a posição do terminal retentivo do grampo, em relação a quantidade de retenção planejadas, 0,25 $\mathrm{mm} \mathrm{Co}^{-} \mathrm{Cr}, 0,50 \mathrm{~mm} \mathrm{Au}^{3}$.

O plano-guia referente aos dentes pilares também interfere na retenção. Como controla via de inserção e remoção da prótese, fornecem retenção secundária para as próteses pela limitação das possibilidades de deslocamento existentes ${ }^{7}$. A altura vertical do planoguia deve ser igual à distância percorrida pelo braço retentivo do grampo; se esta situação não acontece, 
pode haver até a perda de retenção do grampo durante a ação da mastigação. A altura mais adequada do plano-guia é por volta de 2 a $3 \mathrm{~mm}$, em casos em que estes valores não sejam alcançados, há necessidades de preparos dentais. Os planos guias promovem uma certa retenção friccional da prótese, através das somatórias áreas de contato dos dentes pilares, o que favorece a não disseminação de forças horizontais nos suportes dentais. Nos casos de planos guias muito pequenos ou ausentes, não se faz possível manter a trajetória de inserção da PPR, podendo haver deslocamento da prótese pela perda da retenção ${ }^{3}$. Quanto mais verticais são as paredes axiais dos dentes pilares (planos-guia) paralelas a via de inserção, menores são as possibilidades de deslocamento. Na ausência do paralelismo, os traumas aos dentes remanescentes são inevitáveis e a retenção do grampo será menor ou praticamente não existirá?

\section{Mecanismos de Estabilidade}

A estabilidade resiste às forças multilaterais pela ação dos componentes rígidos da PPR, como grampos de oposição, conectores, selas e dentes artificiais. A condição do rebordo ósseo, fibromucosa, musculatura paraprotética, equilíbrio da oclusão, plano-guia, retenção indireta, além do número, grau de mobilidade e distribuição de dentes pilares podem auxiliar neste processo $\mathrm{O}^{3,5,9}$.

A ação dos retentores indiretos é fundamental na estabilidade da PPR, por melhorar a distribuição do suporte dental e minimizar as possíveis movimentações da prótese. O grampo de oposição pelos princípios de reciprocidade e o paralelismo de inserção com o plano-guia auxiliam na estabilização do dente pilar e da PPR (Fiori); o sistema de conexão rígida também promove a estabilidade protética ${ }^{10}$. A adaptação das selas ao rebordo residual, ajuste oclusal equilibrando as forças mastigatórias e em movimentos excursivos da mandíbula, além do bom relacionamento com as estruturas paraprotéticas (bochecha, língua, lábios etc) favorecem a estabilidade da PPR ${ }^{5}$.

\section{Neutralizar ou Minimizar Movimentações em PPR}

$\mathrm{Na}$ busca de neutralizar ou minimizar as possíveis movimentações da PPR, deve-se avaliar, durante o exame clínico do paciente, a condição oclusal, musculatura paraprotética, fonação e patologias associadas que interfiram na reabilitação, como a xerostomia ${ }^{10}$.

Avaliar a condição de suporte, por exame físico e radiográfico, selecionando pilares dentais que apresentem favorecimento periodontal, de integridade coronária e não apresente lesões patológicas ${ }^{10}$.

Identificar a condição da fibromucosa e osso alveolar residual principalmente em casos de extremo livre; pois caso se configure em prognóstico desfavorável deve-se traçar estratégias durante o planejamento para contornar a situação ${ }^{10}$. (Quadro 1)

Buscar um planejamento em superfície para aumentar o suporte, retenção e estabilização da prótese; em casos de distribuição linear sem a possibilidade de retenção indireta, a literatura sugere fazer uso de implantes como retenção adicional ${ }^{5,7,2}$. . Quanto à retenção dos dentes suportes, na tentativa de reduzir os ângulos de convergência e divergência, e assim a convexidade dos dentes, que impede o paralelismo dos dentes suportes à trajetória de inserção, é indicado sejam feitos preparos dentais como recontorno dental e preparos para plano-guia. Deve haver um equilíbrio de retenção em todos dentes suportes do arco, a fim de não promover, quando a prótese for removida, uma ação de rotação, aumentando a carga sobre alguns dentes pilares ${ }^{3}$.

Outro fator a ser destacado é a importância de a retenção manter o suporte dental com integridade periodontal, evitando condições de forças laterais, e optar por desenhos de grampos mais simples e que favoreçam a estética da reabilitação oral ${ }^{3}$. Em relação a estabilidade dos dentes suportes, os braços de oposição do grampo devem ser localizados de modo que a prótese seja estabilizada contra movimentos horizontais. Essa estabilização só é possível com o uso de braços de grampo rígidos, conectores menores e um 
conector maior rígidos. Forças horizontais aplicadas de um lado do arco dental são suportadas pelos componentes estabilizadores do lado oposto, fornecendo estabilidade de um lado a outro do arco ${ }^{\underline{ }}$.

Para evitar o movimento de rotação frontal, deve-se buscar um posicionamento dental em zona neutra, rigidez e adequada seleção do conector maior, ajustar a oclusal, áreas basais abrangentes e optar por moldagens funcionais para estabelecimento dos limites funcionais contendo os movimentos de rotação frontal 3,5 . A moldagem funcional não é fundamental em casos de prótese dentossuportada, devido a mucosa não participar da transmissão de força mastigatória ${ }^{5}$. Em relação ao movimento de rotação horizontal, almeja-se uma correta escolha do conector maior, oclusão equilibrada e adequado recobrimento em casos com extensão distal ${ }^{3}$.

As forças horizontais sempre vão existir em algum grau, pelas tensões laterais que ocorrem durante a mastigação, o bruxismo, hábitos parafuncionais, por um plano oclusal não restabelecido, dentes mal posicionados no arco e relações anormais entre arcos. Assim, a construção de uma oclusão que esteja em harmonia com a dentição oposta e que esteja livre de interferência durante os movimentos excêntricos da mandíbula, montagem até $1^{\circ}$ molar para diminuir o braço de potência, pode minimizar a magnitude das tensões laterais no suporte dental ${ }^{Z, 9}$.

Em casos dentomucossuportados com extensão distal, para conter os movimentos de rotação sagital, deve-se usar a estratégia de localização de apoios, em dentes pilares, distante do extremo livre (apoio mesial), a fim de minimizar as movimentações em torno da linha de fulcro e evitar danos aos dentes pilares, formando um movimento de alavanca de segundo gênero ou inter-resistente. Em caso de movimentos que comprimam os tecidos da área basal pela prótese (rotação distal), haverá o mesmo direcionamento da força de potência e ação da resistência nos suportes dentais, tornando a ação do grampo de retenção passivo. Nos casos das forças que distanciam a área basal da prótese dos tecidos orais (rotação mesial), os grampos de retenção irão atuar ativamente no mesmo sentindo da força de potência? .

Como o apoio mesial torna-se mais distante do eixo de rotação, durante o movimento para distal da sela, o grampo perde o contato do terminal de retenção com o dente pilar. Desse modo, promove o deslocamento do grampo de retenção em direção a cervical, região de mais baixo ângulo de convergência, evitando torque sobre o dente pilar ${ }^{3}$. Caso o apoio fosse localizado próximo ao extremo livre, haveria sentidos opostos entre a força de potência e a ação da força de resistência, sobrecarregando o suporte dental através de forças laterais nocivas à saúde periodontal? .

Teoricamente, o movimento vertical da sela pode ser anulado com o uso de retentores indiretos que auxiliam os retentores diretos na prevenção do deslocamento da base da prótese, opondo-se ao movimento de rotação. Esses devem ser posicionados frente à linha de fulcro e sobre esta traçar uma linha perpendicular formando ângulo de $90^{\circ}$ (reta mediatriz) e equidistante dos apoios mais posteriores, para que se alcance o retentor indireto ideal, o mais distante possível da linha de fulcro3,10.

Dependendo do elemento dental, por exemplo, os dentes anteriores, este retentor indireto pode ser substituído por retentores bilaterais e simétricos em pré-molares. Geralmente os incisivos são a localização mais efetiva para um retentor indireto, porém estes elementos dentais podem não ser resistentes o bastante para suportar a retenção. Pela reduzida estrutura de esmalte e paredes muito inclinadas, também pode gerar trauma lingual e até mesmo interferência oclusal. Há situações em que o canino mais próximo ou a superfície mésio-oclusal do primeiro pré-molar podem ser a melhor localização. Embora esses dentes não estejam tão distantes da linha de fulcro, nessa condição, dois retentores indiretos próximos à linha de fulcro são usados para compensar o comprometimento em distância. Nesta escolha, se faz necessário avaliar a condição do suporte dental para atuar na retenção indireta e a extensão do extremo livre, variáveis que podem interferir na neutralização dos movimentos protéticos ${ }^{7}$. 
A depender da situação clínica do arco parcialmente edêntulo, os retentores indiretos podem se apresentar como apoios, retentores, grampo contínuo de Kennedy e conectores maiores, como a placa lingual ${ }^{5,9}$. Vale ressaltar que um retentor indireto pode atuar também como retentor direto quanto ao suporte da carga mastigatória, ou seja, nos casos em que os retentores indiretos sejam dentes pilares ${ }^{3}$. Quando os retentores indiretos recebem grampo, a retenção da prótese e sua estabilidade horizontal são aumentadas pela ação dos grampos de oposição, impedindo movimentações laterais da PPR ${ }^{5}$.

O uso de implantes osseointegrado em região distal pode atuar como elemento rígido para impossibilitar o movimento de alavanca e pode ser avaliado em situações de pouca capacidade de suporte da extensão distal ${ }^{5,7}$, ou em casos críticos de Classe III e Classe IV de Kennedy com extensos espaços protéticos ${ }^{10}$. No entanto, a opção biomecânica não será tratada nesta revisão.

Para uma prótese sem extensão distal dentossuportada, o movimento potencial é menor, porque a resistência à carga funcional é dada pelos dentes, que não variam muito na habilidade de dar esse suporte; fazendo com que os desenhos para as próteses sejam menos variáveis. Os apoios podem ser localizados na mesial ou distal dos dentes suportes, dependendo do grampo usado e localização do espaço protético. Em geral, o apoio deve ser adjacente ao espaço protético. Em tais condições, ocorrem pequenos movimentos de intrusão de elemento dental no alvéolo ${ }^{3,10}$, sendo assim, a prótese parcial dentossuportada não gira sobre um fulcro, como o faz a prótese parcial com extremo livre ${ }^{7}$.

É importante que os mecanismos de retenção e estabilidade, que buscam manter a prótese em posição, sejam avaliados individualmente; em seguida, conjuntamente com a classificação do arco, transmissão de carga mastigatória da prótese e sistema estomatognático ${ }^{5}$.

\section{Aplicação Clínica}

Serão apresentados estudos biomecânicos com base em estudos significantes das Classes de Kennedy apenas como recurso didático para trabaIhar o tema. O profissional após realizar o exame clínico, a moldagem de estudo, classificar o arco parcialmente edêntulo, deve estudar as condições biomecânicas do arco para traçar uma estratégia que vise neutralizar ou minimizar as movimentações da prótese. Durante o exame clínico e radiográfico, devem ser investigados: as condições de suporte dental e suporte do rebordo residual, oclusão, musculatura paraprotética, fonação e patologias associadas; a retenção de dentes pilares e o paralelismo entre dentes pilares serão investigados durante o delineamento do modelo de estudo. Todas essas informações virão a ser somadas ao ser definido o planejamento final do desenho da PPR.

Sugere-se, durante o estudo biomecânico do arco, observar as seguintes variáveis: Dentes Pilares, Distribuição de Dentes, Linha de Fulcro, Retenção Direta, Apoios Principais, Retenção Indireta, Apoios Secundários, Braço de potência e resistência, Transmissão carga mastigatória. E que o cirurgiãodentista desenhe em plano o arco a ser reabilitado com PPR, e sobre esse arco trace a linha de fulcro e reta mediatriz, descreva as variáveis em questão e, por fim, anexe esse estudo à ficha do paciente.

No caso Classe I de Kennedy com ausência dos elementos 37 a 35 e 47 a 45, apresenta-se uma condição de prótese com extremo livre em que podem ocorrer movimentos de rotação sagital, frontal e horizontal. Retentores diretos são 34 e 44 em distribuição linear. Tais elementos irão receber apoios mesio-oclusal, a fim de transmitir a carga mastigatória ao suporte dental e diminuir o torque dental durante a rotação sagital, como também grampos para retenção da prótese. Para neutralizar ou minimizar os movimentos de alavanca das selas, deve-se buscar uma retenção indireta ao traçar a reta mediatriz perpendicular à linha de fulcro, sendo os retentores ideais 41 e 31 . Esses elementos dentais são pouco resistentes pela reduzida estrutura de esmalte, e podem ser substituídos por retentores bilaterais e simétricos ${ }^{3,10}$, como o canino mais próximo ${ }^{ }$. Assim, 33 e 43 foram determinados como retentores indiretos, promovendo a estabilidade e tornando a distribuição de dentes superficial, aumentando a área de ação da prótese desde que o braço de potência no arco seja maior que o braço de resistência, e recebendo apoios secundários. Os movimentos de rotação frontal e horizontal serão minimizados pelo posicionamento dental em zona neutra, rigidez do conector maior, ajuste oclusal, áreas basais abrangentes $\frac{3,5}{,}$ montagem até $1^{\circ}$ molar para diminuir o braço de potência 9 . E a transmissão de carga mastigatória é dentomucossuportada, decorrente dos extremos livres distais. (Quadro 2) 


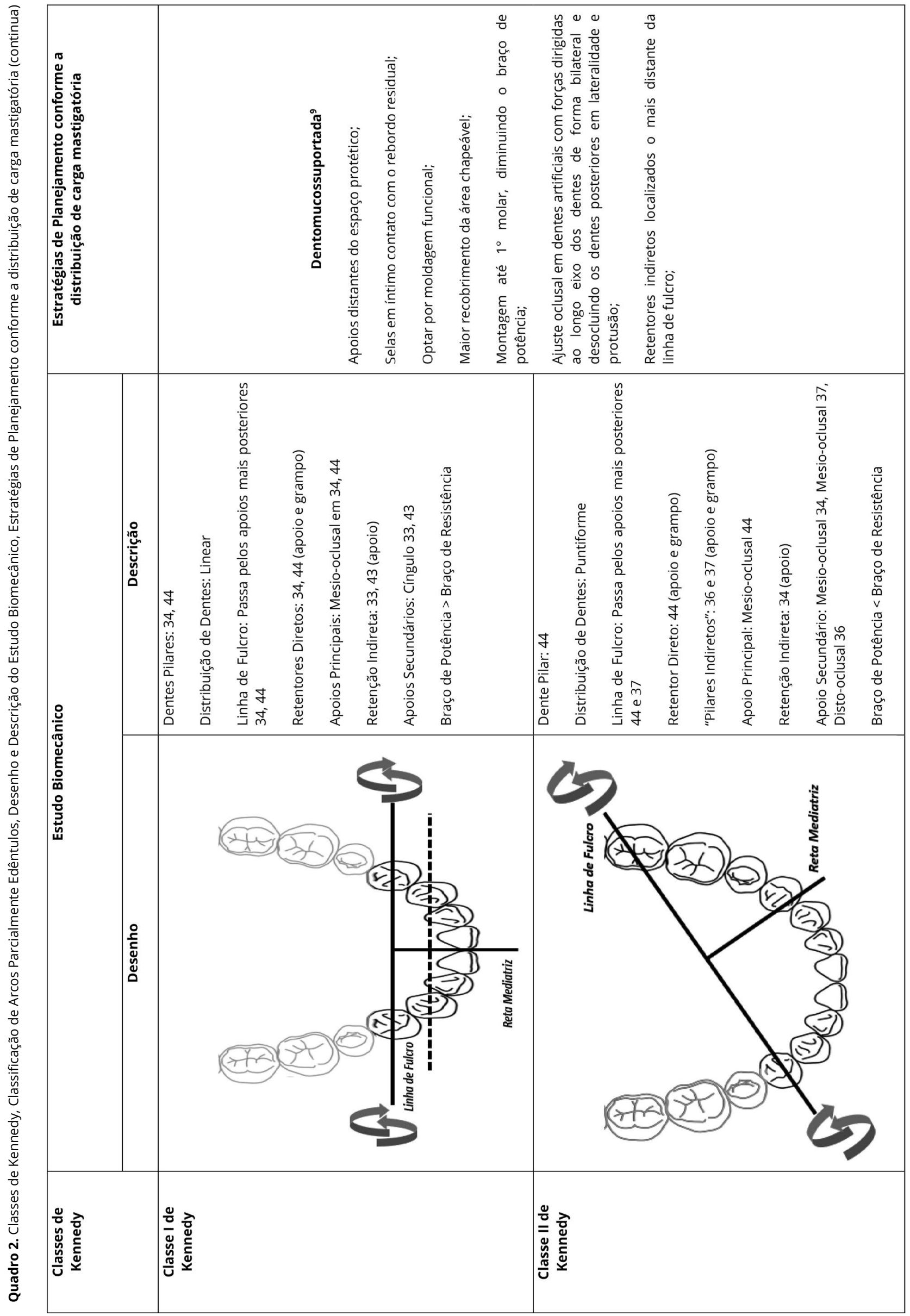




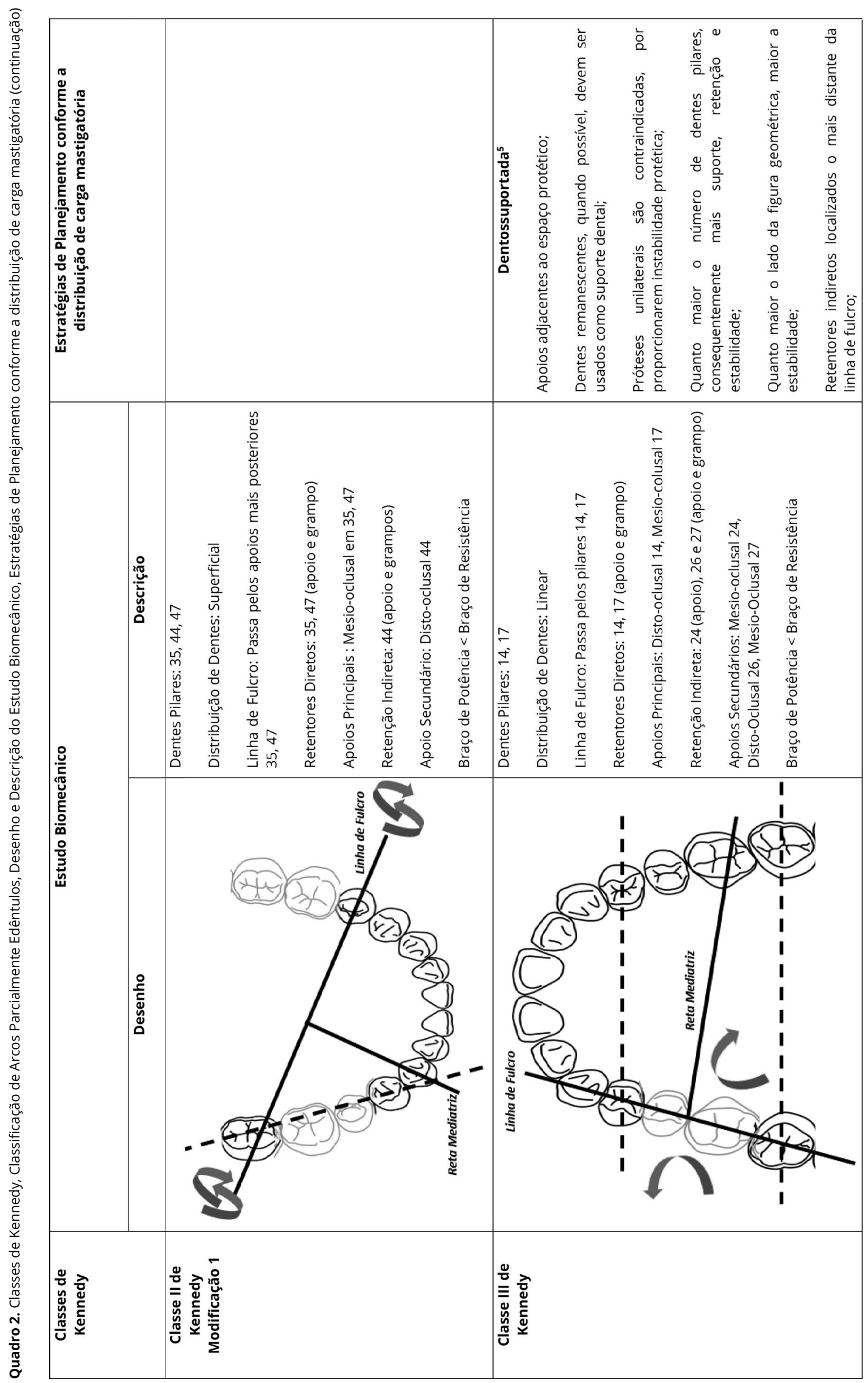




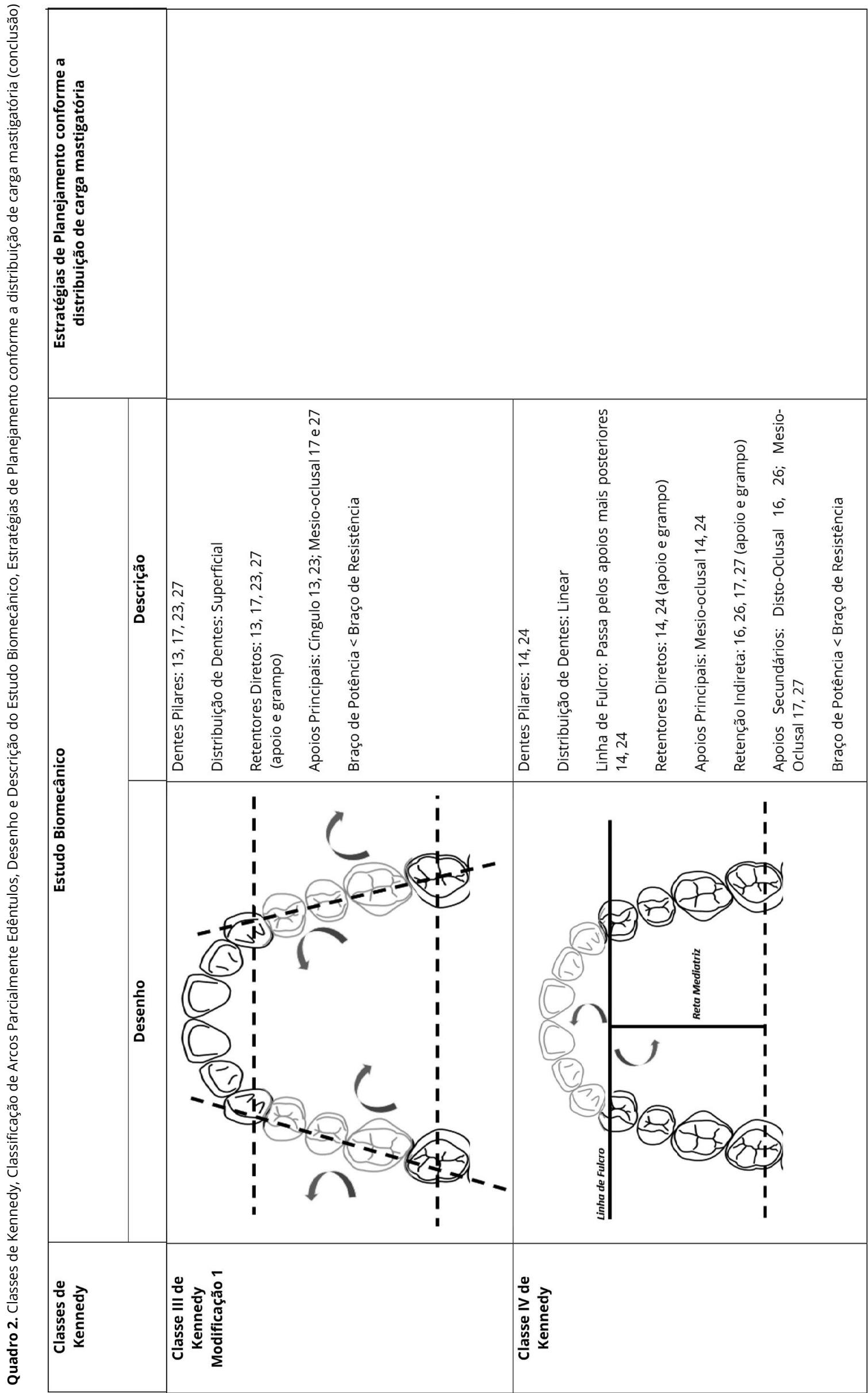

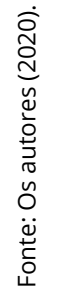


Caso clínico Classe II de Kennedy, com ausência dos elementos dentais 45 a 47, condição de prótese com extremo livre unilateral. Embora o braço de potência seja menor que o braço de resistência, já que há mais dentes presentes que ausentes, a distribuição puntiforme do retentor direto 44 não favorece a distribuição de carga mastigatória. A literatura aponta que a distribuição de dentes pilares no arco apresenta-se mais importante que o número desses $3,5,9,10$. Há necessidade de outro suporte dental a ser selecionado no hemiarco oposto, diagonalmente o mais distante do dente pilar, que será o 37, um "pilar indireto" que receberá apoio e grampo para suporte das cargas mastigatórias, tornando a distribuição de dentes linear ${ }^{5}$. A linha de fulcro passa pelos apoios mais posteriores 44 e 37, e para estabilizar a prótese. o 34 atuará como retentor indireto ideal e receberá apoio mesio-oclusal, já modificando a distribuição de dentes para superficial. Pela condição de alavanca posterior, o dente pilar irá receber grampo de retenção e apoio mesio-oclusal, a fim de transmitir a carga mastigatória ao suporte dental e diminuir o torque dental durante a rotação sagital, Para aumentar a retenção da prótese e favorecer o suporte, grampos gêmeos e apoios entre os elementos dentais 36 e 37 poderiam ser utilizados. A neutralização dos demais movimentos de rotação, com exceção da montagem até o $1^{\circ}$ molar e a transmissão de carga mastigatória, se aplicam como no caso de Classe I de Kennedy. (Quadro 2)

No caso de Classe II de Kennedy Modificação 1, a resolução é muito semelhante à condição sem modificação, pois os dentes pilares já apresentam distribuição superficial de dentes. Um arco com ausência 35, $36,46,47$ apresenta 37, 34, 45 como retentores diretos. O elemento dental 34 pode atuar como retenção indireta, corroborando com a literatura 3,5 , desde que se opõe à linha de fulcro, que passa por 45 e 37. (Quadro 2)

Caso de Classe III de Kennedy com ausências dos elementos dentais 15 e 16. Para solução biomecânica deste arco, Cummer propôs a confecção de prótese unilateral, pois, para ele, a retenção indireta não era necessária, por ser uma condição de ausência dental unilateral e intercalar (Classe III de Cummer)12,13. Sabe-se que a PPR unilateral é contraindicada e foi muito criticada por favorecer a aspiração pelo paciente, pela retenção reduzida ${ }^{12}$ e por falta de estabilidade pela ação de forças horizontais (vestíbulo-linguais) que podem deslocá-la, ou seja, o prognóstico biomecânico é desfavorável ${ }^{5}$.
Com a preocupação pelo planejamento do desenho através da publicação da Classificação de KennedyApplegate, a retenção indireta em casos Classe III de Kennedy deve ser proposta através do hemiarco oposto ${ }^{13}$. Mesmo com braço de potência inferior ao braço de resistência, a distribuição de dentes linear não é favorável à estabilidade da prótese. Esta pode torna-se superficial com a soma de retentores indiretos do lado oposto do arco, que além de proporcionar a estabilidade frente à rotação no plano horizontal, também gera maior suporte dental e retenção da prótese.

A retenção indireta, para o arco Classe III de Kennedy com ausências dos elementos dentais 15 e 16, será obtida através da reta mediatriz que vai ao encontro do 26 , determinando-o como retentor indireto, e promovendo um planejamento em superfície através da figura triangular. Porém, com a adição de mais uma retenção indireta no 24 , através de apoio mesio-oclusal distante da zona de instabilidade, a figura geométrica passa ser quadrilateral, aumentando a área de componentes da PPR sobre o arco e, consequentemente, melhorando a estabilidade e do suporte. $\mathrm{O}$ uso de grampos gêmeos e apoios entre os elementos dentais 26 e 27 aumenta substancialmente a retenção. Por fim, é um caso clínico com transmissão de carga mastigatória dentossuportada, com suporte apenas dental e a sela apenas apoiada sobre o tecido mucoso, como também o espaço protético é integrado à figura geométrica. (Quadro 2)

Em casos de Classe III de Kennedy Modificação 1, a ausência dos elementos dentais 14 a 16 e 24 a 26 faz com que os dentes pilares $(13,17,23,27)$ estejam dispostos em figura geométrica quadrilateral com distribuição de dentes em superfície, condição favorável ao suporte, retenção e estabilidade da prótese. Como o braço de resistência é maior que o braço de potência, há maior número de dentes no arco. Todos os dentes pilares também são retentores diretos e promovem o suporte dental através dos apoios; o uso de grampos nestes elementos dentais promove a retenção da PPR. Segundo Cummer, um arco no qual três ou mais dentes pilares atuam na retenção direta, uma relação triangular ou quadrilateral, não requerem o uso de retenção indireta ${ }^{13}$. A estabilidade da prótese ocorre por meio dos dentes pilares do lado oposto, e vice-versa, através dos componentes rígidos da prótese (braço de oposição do grampo e conectores), evitando o movimento de rotação horizontal da PPR. As forças horizontais aplicadas de um lado do arco dental são suportadas pelos componentes estabilizadores no lado 
oposto ${ }^{7}$ e pela ação dos grampos de oposição, impedindo movimentações laterais da prótese ${ }^{5}$. (Quadro 2)

No caso de Classe VI de Kennedy, com ausência dos elementos dentais 13 a 23, observa-se a distribuição linear por dentes pilares 14 e 24 , braço de retenção superior ao braço de potência. A ação do movimento de rotação horizontal (vestíbulo-lingual) produz instabilidade protética - vale salientar que a convexidade anterior do arco é um fator que pode interferir nesta movimentação e ser verificado durante o exame clínico. A linha de fulcro anterior passa pelos retentores diretos 14 e 24, fazendo com que a busca pela estabilidade se dê pela escolha de retentores indiretos 17 e 27, o mais distante do fulcro, tornando o planejamento em superfície quadrilateral, o que favorece a estabilidade da PPR. Os elementos dentais 14 e 24 recebem apoio mesio-oclusal e grampos; o uso de grampos gêmeos e apoios entre os elementos dentais 16 e 17; 26 e 27 aumenta substancialmente a retenção e suporte da prótese, além da estabilidade pela ação do braço de oposição do retentor. Por fim, também é um caso clínico com transmissão de carga mastigatória dentossuportada 5 . (Quadro 2)

\section{Discussão}

Esta temática apresenta uma escassa literatura com pouquíssimos registros; e as literaturas específicas possuem linguagem muito distinta, sem cronologia dos fatos, e com vários capítulos não sequenciais para tratar a questão da instabilidade da prótese parcial removível. Muitas dessas literaturas não apresentam resoluções clínicas dos problemas biomecânicos, tornando mais difícil a compreensão pelo profissional e principalmente pelos os alunos de graduação.

Segundo o que já foi exposto, é urgente a discussão biomecânica em PPR, devido à grande demanda de pessoas que necessitam repor dentes perdidos no Brasil ${ }^{14}$. O planejamento dessas próteses é muitas vezes negligenciado pelo cirurgião-dentista ${ }^{4}$, causando aos usuários danos periodontais em suporte dental, traumas em tecido mucoso, aceleração da reabsorção óssea $3,5,9,10$ e desconforto ${ }^{?}$.

O estudo da biomecânica do arco é muito importante, uma vez que antecipa os elementos dentais que devem ser avaliados quanto à retenção durante o delineamento, por serem retentores diretos ou retentores indiretos que receberão grampos. Além disso, indica como será o desenho da prótese, facilitando a escolha de grampos e conectores, conforme a condição clínica e localização de apoio. Ele também prevê a necessidade de moldagem funcional, até mesmo a longevidade da prótese, pois se não houver suporte satisfatório, retenção e estabilidade contra a ação das forças funcionais e parafuncionais, não haverá sucesso clínico da reabilitação protética.

O estudo biomecânico das Classes I e II de Kennedy são semelhantes, mas não iguais, mesmo que os arcos parcialmente edêntulos dessas classes apresentem extremos livres. A condição biomecânica da Classe II de Kennedy é mais favorável por apresentar maior braço de resistência ou distribuição de dentes pilares em superfície; a Classe I de Kennedy, no entanto, é menos favorecida pelo braço de potência geralmente maior que a resistência e pela presença de dois extremos livres intensificando os vetores de instabilidade protética.

Algumas literaturas apresentam apenas o estudo biomecânico de próteses dentomucossuportadas com extensão distal, e uma crítica deve ser feita a isso, pois as próteses dentossuportadas, como casos de Classe III de Kennedy, também apresentam instabilidade quanto à ação de forças horizontais e necessitam de retentores indiretos para proporcionar a estabilidade protética. Talvez tal condição deva-se ainda aos conceitos biomecânicos de Cummer (1921), no quais casos de dentes pilares dispostos unilateralmente (Classe III de Cummer / Classe III de Kennedy) e dentes pilares dispostos em forma triangular ou quadricular (Classe IV de Cummer / Classe III de Kennedy) não necessitam de retenção indireta ${ }^{13}$. Esse paradigma já foi quebrado, pois dependendo de como estiverem dispostos os dentes pilares no arco, a instabilidade frente a movimentos vestíbulo-linguais é real e necessita de retenção indireta sobre suportes dentais. No entanto, as próteses para arcos Classe IV de Kennedy geralmente são consideradas dentossuportas e apresentam planejamento clássico com a presença de retentores indiretos. Para Cummer, o arco Classe IV de Kennedy corresponde à Classe II de Cummer, a qual apresenta dentes pilares em posição diametral e o arco está sujeito aos movimentos de alavanca anterior, assim necessitando de retenção indireta ${ }^{10}$. 
Uma outra preocupação e crítica se deve à literatura generalizar os casos de prótese dentomucossuportada como arcos com extremos livres, Classe I e II de Kennedy; e casos de prótese dentossuportada, como arcos sem extremos livres Classe III e IV de Kennedy. A classificação de um arco parcialmente edêntulo é essencial para iniciar o planejamento do desenho, porém a classificação de Kennedy apresenta base topográfica e não prevê extensão do espaço protético. Portanto, poderá haver condições críticas de Classe III e IV de Kennedy que apresentarão transmissão de carga mastigatória dentomucossuportada. Nestes casos, deve-se usar as estratégias para os casos de extremos ditais como posicionamento dental em zona neutra, ajustar a oclusal, áreas basais abrangentes e optar por moldagens funcionais, adequada seleção do conector maior, e apoio distante do espaço protético em condição de alavanca anterior, Classe IV de Kennedy.

A extensão do espaço protético foi uma variável proposta por alguns autores em suas classificações de $\operatorname{arcos}^{12}$, como na Classificação de Baylin (1928), que não foi bem aceita pela comunidade científica por não proporcionar uma visualização imediata para o planejamento $\frac{15}{}$. Sugiro fazer uso da Lei de Ante, que mensura a área de ligamento periodontal dos dentes pilares, a fim de definir a possibilidade apenas de suporte dental dos dentes pilares remanescentes frente aos dentes ausentes, nestas condições de Classe III e IV de Kennedy extremas. Já Fiori propõe que, para definir a transmissão de carga mastigatória sobre um arco, deve-se observar se a figura geométrica formada abrange os espaços protéticos; caso sim, temos uma prótese dentossuportada, mas quando há espaços edêntulos não incluídos nesta figura, a prótese é dentomucossuportada. O uso do artifício da classificação do arco para o estudo biomecânico também foi realizada neste artigo por uma questão didática. No Brasil, a classificação de Kennedy é amplamente divulgada nas escolas dentais $5^{5}$, mas se faz importante destacar os casos críticos e reafirmar a necessidade de serem utilizadas classificações com bases topográfica, biomecânica e de transmissão de esforços mastigatórios aos elementos dentais e ao rebordo residual no planejamento do desenho da $\mathrm{PPR}^{16}$.
Talvez o reduzido relato de estudos biomecânicos em PPR convencionais se deva à consolidação da implantodontia e ao uso de implantes geralmente em região distal ou anterior, para favorecer a retenção e estabilidade de próteses removíveis não convencionais. Sobre essa modalidade de prótese removível, há bastante literatura sobre a condição biomecânica, que é uma limitação desta revisão não ter abordado a questão.

Novos estudos devem ser propostos quanto à PPR convencional, principalmente com a ferramenta de elemento finito e a avalição das tensões sobre os suportes dental e mucoso em casos de extensos espaços protéticos sem extensão distal. Atualmente, devido à tecnologia digital na PPR, tais pesquisas tornam-se mais fáceis de serem realizadas.

\section{Considerações finais}

O estudo biomecânico da prótese parcial removível convencional deve ser conduzido com base no suporte, retenção e estabilidade. Quando identificadas características clínicas que interfiram em mecanismos de retenção e estabilidade, faz-se necessária a adoção de estratégias para minimizar a movimentação da prótese. Tais estratégias dão maior recobrimento da área chapeável, montagem até $1^{\circ}$ molar, ajuste oclusal com forças dirigidas ao longo eixo dos dentes artificiais, desoclusão dos dentes posteriores em lateralidade e protusão, retentores indiretos localizados o mais distante da linha de fulcro.

\section{Contribuição dos autores}

Figueiredo VMG, Arcoverde LMM responsabilizaram se pela escrita do artigo. Grangeiro MTV responsabilizou-se pela correção do artigo.

\section{Conflitos de interesses}

Nenhum conflito financeiro, legal ou político envolvendo terceiros (governo, empresas e fundações privadas, etc.) foi declarado para nenhum aspecto do trabalho submetido (incluindo, mas não se limitando a subvenções e financiamentos, participação em conselho consultivo, desenho de estudo, preparação de manuscrito, análise estatística, etc.). 


\section{Referências}

1. Poluha RL, Soares FFC, Canales GDT. Metallic frames of removable partial denture: a planning. Braz Dent Sci. 2018;21(4):418-423. http://dx.doi.org/10.14295/bds.2018. v21i4.1628

2. Benso B, Kovalik AC, Jorge JH, Campanha NH. Failures in the rehabilitation treatment with removable partial dentures. Acta Odontol Scand. 2013;71(6):1351-5. http://dx.doi.org/10.3109/0001 6357.2013.777780

3. Kliemann C, Oliveira W. Manual de Prótese Parcial Removível. 1.ed. São Paulo: Santos; 1999.

4. Torban P, Freitas Junior AC, Braz R, Duarte Filho ESDD. Avaliação Qualitativa e Quantitativa dos Planejamentos de Próteses Parciais Removíveis Enviados pelos Dentistas aos Laboratórios de Prótese Dentária. Odontol. Clín.-Cient, 2016;15(2).

5. Di Fiore SR. Atlas de prótese parcial removível: princípios biomecânicos, bioprotéticos e de oclusão. São Paulo: Santos, SP; 2013.

6. Bohnenkamp DM. Removable Partial Dentures: clinical concepts. Dent Clin North Am. 2014;58(1):69-89. http://dx.doi. org/10.1016/j.cden.2013.09.003

7. Carr AB, Brown DT. McCracken: prótese parcial removível. 12.ed. Rio de janeiro: Elsevier; 2012.

8. Jorge JH, Quishida CCC, Vergani CE, Machado AL, Pavarina AC, Giampaolo ET. Clinical evaluation of failures in removable partial dentures. J Oral Sci. 2012;54(4):337-42. http://dx.doi.org/10.2334/ josnusd.54.337
9. Carreiro AFP, Batista AUD. Prótese parcial removível contemporânea. São Paulo: Santos; 2013.

10. Todescan R. Atlas de Prótese Parcial Removível. 2.ed. São Paulo: Santos; 2001.

11. Correia ARM, Lobo FDS, Miranda MCP, Araújo FMSF, Marques TMS. Evaluation of the Periodontal Status of Abutment Teeth in Removable Partial Dentures. Int J Periodontics Restorative Dent. 2018;38(5):755-760. http://dx.doi.org/10.11607/prd.2855

12. Miller EL. Systems for classifying partially dentulous arches. J Prosthet Dent. 1970;24(1):25-40. http://dx.doi.org/10.1016/00223913(70)90271-4

13. Lourenção CG. O Arco Dentário Parcialmente Desdentado e suas Classificações [dissertação]. São José do Rio Preto: Escola Técnica Estadual Philadelpho Gouvêa Netto; 2010.

14. Moreno A, Haddad MF, Goiato MC, Rocha EP, Assunção WG, Gennari Filho $\mathrm{H}$ et al. Epidemiological Data and Survival Rate of Removable Partial Dentures. J Clin Diagn Res. 2016;10(5):84-7. http://dx.doi.org/10.7860/JCDR/2016/16638.7816

15. Galagali G, Mahoorkar S. Critical Evaluation of Classification Systems of Partially Edentulous Arches. International Journal of Dental Clinics. 2010;2(3):45-52.

16. Gil C, Nakamae AEM. Índice de qualidade do trabalho protético (IQP): um estudo metodológico. RPG Ver Pos-Grad. 2000;7(1):38-46. 